\title{
VICIOS REDHIBITORIOS: CARACTERIZACIÓN JURÍDICA Y FUNDAMENTOS ECONÓMICOS DE UNA INSTITUCIÓN ANCESTRAL
}

\author{
CRISTIAN RICARDO A. PIRIS \\ UNIVERSIDAD NACIONAL DEL NORDESTE
}

ARGENTINA

"Hay pícaros suficientemente pícaros para comportarse como personas honradas".

Napoleón Bonaparte. 


\section{RESUMEN}

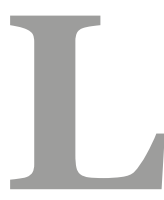

a pregunta central en materia de vicios redhibitorios, es si entregar una cosa con vicios ocultos puede calificarse como cumplimiento del contrato. En el Derecho, desde tiempos de la antigua Roma se ha entendido que no. Pero entonces cabe la siguiente pregunta ¿̇por qué la existencia de vicios ocultos no sirve para que se declare, simplemente, que ha sido infringida la obligación principal de entregar la cosa vendida en las condiciones acordadas? La única respuesta consistente es apelar a razones de utilidad, a cuestiones prácticas para facilitar el tráfico. El régimen de los vicios ocultos se sustenta en fundamentos económicos, no jurídicos como en la evicción, y tiende a asegurar al adquirente una posesión útil (Castán Tobeñas, 1993, p. 121). Es un supuesto de responsabilidad objetiva del transmitente, quien debe la garantía aunque sea de buena fe. La existencia de mala fe solo sirve para agravar la situación de éste, y habilitar una indemnización por daños y perjuicios, pero ello es independiente de la restitución del precio que se debe en todos los casos. Queda claro que lo que se pretende es restablecer el equilibrio prestacional. El adquirente ha pagado un precio con el fin de obtener un bien, teniendo en miras determinadas utilidades de la cosa. Esas utilidades, no surgen de su imaginación sino que son propias del destino de la cosa, pero si no sirve para eso, el comprador se ve perjudicado. De allí que esta garantía permita la restitución recíproca del precio y la cosa, o bien la disminución del precio en medida equivalente al costo del defecto. El Análisis Económico del Derecho coincide con la solución pero le da al asunto un nuevo abordaje mirando la utilidad social y no el equilibrio prestacional. Los vicios son casos de daños bilaterales, en cuya detección pueden invertir tanto adquirente como enajenante, y corresponde cargar con los riesgos del mismo a aquel sujeto que de manera más económica pueda evitarlos.

Palabras Clave: contratos, defectos, responsabilidad, garantías.

\section{ABSTRACT}

The central question concerning latent defects is whether delivering a thing hidden defects can be classified as contract compliance. In the law, since the time of ancient Rome was not understood. But then there is the question: why the existence of hidden defects no use to declare simply has been infringed the principal obligation to deliver the goods sold in the agreed conditions? The only consistent answer is appealed to for reasons of utility, to practical issues to facilitate traffic. The system of hidden defects is based on economic foundations, not legals as eviction, and tends to assure the purchaser a useful possession (Castan Tobeñas, 1993. p. 121). It's a course of strict liability of the transferor, who owes warranty terms albeit in good faith. The existence of bad faith only serves to aggravate the situation of him, and 
enable compensation for damages, but this is not refund the price to be in all cases. It's clear that what is intended is to restore balance between benefits. The purchaser has paid a price to get a good, considering determined view profits of the thing. These utilities do not arise from his imagination but are themselves the fate of the thing, but if not used to that, the buyer is impaired. Hence this guarantee allows reciprocal refund of the price and the thing or the price decrease in extent equivalent to the cost of the defect. The Economic Analysis of Law coincides with the solution but gives the issue a new approach looking at the social utility and not the benefits balance. Vices are cases of bilateral damages; in which detection can invest both buyer and seller, and corresponds bear the risk of it to that guy that manera cheaper can avoid them.

Keywords: contracts, defects, liability, implied warranties.

El Derecho Contractual moderno es una zona volcánica, caracterizada por cuestionamientos a las instituciones fundamentales, nuevos desarrollos, concepciones encontradas, conflicto de valores, una permanente tensión entre justicia y eficiencia, microsistemas que se separan, etc., lo que hace que hayan muchas cuestiones controvertidas. Pero en lo que respecta a vicios redhibitorios nos encontramos en una ínsula de relativa calma.

El objetivo del presente trabajo no es repasar un tema clásico carente de actualidad, sino revisar una institución jurídica de larga prosapia para aportar un más extenso y profundo conocimiento sobre ella, sobre todo destacando sus fundamentos económicos, sin los cuales resulta muy difícil comprender el sentido de las soluciones jurídicas adoptadas. Estoy convencido que ello resulta especialmente relevante en estos momentos de transición donde nos preparamos a recepcionar una nueva legislación civil y comercial, que moderniza este instituto pero manteniendo la estructura clásica. La caracterización de los vicios redhibitorios en el marco de los vicios ocultos, será objeto de otro trabajo que se encuentra en elaboración.

Por lo general este es un tema que suele ser visto muy rápidamente, básicamente describiendo la legislación y agotando allí el análisis, pero en cambio tiene aristas que lo hacen sumamente interesante y por donde la doctrina nacional ha transitado poco.

El instituto tiene su origen en el antiguo Derecho Romano (Enciclopedia, 2007, p. 475). Los vicios redhibitorios nacen "como remedio del comprador exclusivamente frente a la venta de una limitada esfera de supuestos, los jumentos y los esclavos, ha ampliado su margen de maniobra ya desde el derecho romano; inicialmente a cualquier animal dorso domatur y, posteriormente, a todo tipo de compraventa" (Ferrante, 2011, p.5). Asnos y esclavos eran casos paradigmáticos de "res" susceptibles de contener defectos ocultos.

${ }^{1}$ Traducción: cosa, en latín. 
Nuestro Derecho Contractual se inscribe en la tradición continental europea, de corte subjetivista, que pone el centro de gravedad en el acuerdo de voluntades, en la autonomía de la voluntad. En cambio la corriente objetivista, propia del common law, pone el centro de gravedad en el equilibrio de las prestaciones. El common law es tributario directo del antiguo Derecho Romano, digo directo porque no ha pasado por las elaboraciones iusnaturalistas de los siglos XVIII y XIX que luego se reflejaron en los Códigos. Los romanos cuando regularon los contratos, miraron el mundo con su visión pragmática y no vieron "consensos" sino "intercambios”, el puro consenso no obligaba sino en muy escasas situaciones ${ }^{2}$; lo que generaba obligaciones eran los intercambios. Los romanos no elaboraron una teoría general del contrato, de hecho ni siquiera tuvieron un concepto de contrato en general, lo que conocieron fueron tipos de contratos específicos. Bajo esa lógica se crea la garantía de evicción y vicios redhibitorios en los contratos de compraventa.

Hago esta aclaración para que puedan entender las dificultades que existen para encuadrar estas dos figuras dentro de una matriz subjetivista, de hecho se las estudia en el marco de:

- Las garantías contractuales.

- Como efectos de los contratos onerosos (aunque también se aplican a la división o partición de bienes, por lo que debería tratarse en normas generales (Garrido-Zago, p. 379).

- Dentro de las prescripciones de la obligación de saneamiento.

- Como un tipo de responsabilidad especial (responsabilidad contractual sin culpa - Borda).

A los efectos prácticos, y sin intención de quedar entrampado en la bizantina discusión sobre la naturaleza jurídica, funcionan como garantías legales para el comprador en la medida que los vicios no se hagan presentes, pero en la eventualidad de su emergencia operan como reglas de responsabilidad civil objetiva, en el contexto de contratos sinalagmáticos y con limitación a la reparación del daño intrínseco. Pero es también un caso especial de responsabilidad porque no habilita a la indemnización sino a la rescisión del contrato o la reducción del precio, salvo caso de mala fe del enajenante.

Lo real y concreto es que en el núcleo central de la figura jurídica se omite considerar el aspecto volitivo, no interesa la buena o mala fe del transmitente o el adquirente, lo que prevalece es el equilibrio prestacional. Tanto la evicción como los vicios redhibitorios desnivelan las prestaciones, y por ello se busca restablecer el equilibrio perdido.

Los subjetivistas dicen que en realidad hay una afectación a la voluntad presunta de las partes, porque nadie adquiere un derecho para luego ser privado de él, ni adquiere una cosa que luego será inútil para su destino. En ambos casos se busca el pleno y eficaz cumplimiento del

$\overline{{ }^{2} \text { Era el caso de la compraventa (emptio venditio), el arrendamiento (locatio conductio), la sociedad (societas) y mandato (mandatum). }}$ 
contrato. (Elías, en De Reina Tartiere, 2010, p. 312). No obstante ello, creo que el hecho que la figura se desentienda de la buena fe del enajenante nos da la pauta de la objetividad del instituto ${ }^{3}$.

En primer lugar voy a analizar como está tratado en el Código Civil. También brindaré una visión panorámica de la aplicación práctica que han hecho los tribunales de las prescripciones normativas. Finalmente intentaré levantar la mirada del derecho positivo y analizar el instituto desde otra perspectiva, desde el enfoque del análisis económico del derecho, que nos permitirá descubrir cuestiones interesantes al respecto.

Evicción y redhibitorios, son vicios que afectan los efectos de los contratos. En ambos casos el enajenante garantiza el equilibrio prestacional, aunque se trate de un contratante de buena fe que no conociera la existencia del vicio. Pero evicción y redhibitorios se diferencian en su estructura fáctica; en el primero, el supuesto de hecho es la existencia de un vicio en el derecho transmitido (quien dice ser titular no lo es, o quien dice ser titular pleno no lo es porque pesa un gravamen sobre el derecho); en cambio en los redhibitorios, el vicio afecta la materialidad de la cosa transmitida, haciéndola impropia para su destino.

La evicción busca defender al adquirente frente a la turbación del derecho y se concreta con la actividad del enajenante, actuando en el juicio para protegerlo. En el caso de vicios redhibitorios no hay cuestionamiento alguno sobre el derecho a la cosa (Garrido-Zago, p. 366).

\section{MÉTODO DEL CÓDIGO}

En el derecho antiguo era un capítulo de la compraventa, así se plasmó en el mismo Código Civil francés, pero Vélez lo reguló para la generalidad de los contratos superando las limitaciones clásicas. No obstante ello, si bien evicción como vicios redhibitorios son temas propios de la teoría general del contrato, Vélez siguiendo a Freitas, lo ubicó en medio de los contratos, como si fueran contratos particulares. Se encuentran al finalizar la regulación de la renta vitalicia y antes de los contratos reales. En lo que respecta a los vicios redhibitorios el Código los trata después de la evicción, desde el artículo 2138 al 2181, actuales 2164 a 2155 de la E-0026 (Digesto Jurídico Argentino).

El Código de Comercio (actual F-0067, Digesto Jurídico Argentino) lo prevé en 2 artículos dentro del capítulo de la compraventa, el artículo 675 (472 Cód. Comercio) que alude a vicios o defectos aparentes y el artículo 676 (473 Cód. Comercio) que se refiere a los vicios ocultos.

\footnotetext{
${ }^{3}$ La jurisprudencia ha dicho expresamente que "Ios vicios redhibitorios no constituyen un recurso contra la mala fe del enajenante" y se tratan de garantías para "brindar una mayor seguridad a los negocios jurídicos" CNCiv., sala C, 1999/04/19 - S. de C., V.A y otro c. B., E.C y otro. Publicado en LL,2000-C, 922 (42.747-S) - ED, 183-385.
} 
Redhibitorio viene de redhibir que quiere decir "volver a tener", se emplea en el sentido que a través de ésta figura se obliga al enajenante a volver a tener la cosa enajenada, restituyendo lo percibido. Según el diccionario de la RAE, redhibir es "dicho de un comprador: Deshacer la venta, según derecho, por no haberle manifestado el vendedor el defecto o gravamen de la cosa vendida" En una palabra, redhibición es devolución.

El Código de Vélez define en el artículo 2138 de la ley E-0026 (2164 Cód. Civil) “Son vicios redhibitorios los defectos ocultos de la cosa, cuyo dominio, uso o goce se transmitió por título oneroso, existentes al tiempo de la adquisición, que la hagan impropia para su destino, si de tal modo disminuyen el uso de ella que al haberlos conocido el adquirente, no la habría adquirido, o habría dado menos por ella”.

\section{REQUISITOS QUE DEBEN REUNIR LOS VICIOS PARA QUE PROCEDA LA GARANTÍA}

\section{Existencia de un defecto.}

¿Qué es un vicio o un defecto?

La doctrina civilista no se detuvo especialmente a analizar este punto, podemos decir que no hay un concepto jurídico de defecto por lo que debemos abrevar en el lenguaje común. Vicio y defecto son sinónimos. En el diccionario de la RAE, vicio nos remite a defecto y este es definido como una "carencia de alguna cualidad propia de algo" o una "imperfección en algo o en alguien".

La carencia de ciertas cualidades es algo distinto a la existencia de vicios. "Vicio es una anomalía por la cual la cosa se distingue de todas las otras cosas del mismo género, de la misma especie, de la misma calidad" (Badenes Gasset, T. I. p. 644).

La teoría de los vicios se empezó a desarrollar en el marco del Derecho del Consumidor, porque allí se establece que "daño al consumidor resulta del vicio o riesgo de la cosa..." (artículo 40, Ley de Defensa del Consumidor - F-1884). Es decir, dado que este sistema de responsabilidad especial se activa frente a un daño derivado del vicio o riesgo (que ha sido entendida como defecto) fue allí donde se elaboraron las taxonomías de vicios (de fabricación, construcción, diseño, de información, y de conservación), que era algo a lo cual la dogmática civilista había prestado poca atención.

El Código de Vélez no discriminaba según tipo de defectos, como si lo hace el futuro Código Civil y Comercial. En este cuerpo normativo no solo se regulan los vicios redhibitorios, sino los vicios ocultos en general. Pero tiene la particularidad que cuando va a definir qué es un vicio oculto en general dice "los defectos no comprendidos en las exclusiones del artículo 1053”, es decir en lugar de definir un objeto por el conjunto de sus propiedades, lo caracteriza por lo que no es, lo cual constituye un grave error en lógica. 
En el Derecho Europeo se está produciendo "la extensión del concepto de vicio -o defecto- en algo más amplio y así se llega al moderno concepto de falta de conformidad en el caso de compraventa o al concepto de prestación defectuosa para los demás contratos" (Ferrante, 2011, p. 6). A esa evolución conceptual aportaron la Directiva 1999/44 CE, Draft Common Frame of Reference, Principles of European Contract Law, Convención de Viena sobre los contratos de compra venta internacional de mercaderías (artículo 35).

II. Defecto desconocido por el adquirente.

El vicio no debe ser conocido, ni lo pudiera ser, por el adquirente. El artículo 2144 de la ley E-0026 (2170 Cód. Civil), establece que "El enajenante está... libre de la responsabilidad de los vicios redhibitorios, si el adquirente los conocía o debía conocerlos por su profesión u oficio”.

Un vicio conocido por el adquirente es equiparable al vicio aparente, es decir, no oculto, y por el cual no se debe garantía. Si el vicio es conocido por el adquirente las reglas de la buena fe mandan a no deshacer lo acordado, porque se ha tenido en cuenta la cosa con sus defectos al momento de contratar. En el peor de los casos se ha considerado que dichos defectos no han tenido entidad como para afectar al objeto del negocio o ya se han tenido en cuenta al momento de aceptar el monto del precio a pagar. Frente a un vicio conocido no hay defraudación de expectativas.

Alterini (2009, p. 501) es muy claro en este punto, según las reglas generales en materia de obligaciones, frente el intento del deudor de cumplir con un objeto que adolece de un defecto ostensible, el acreedor puede:

- Rechazar el pago por carencia de requisito de identidad o integridad de la cosa.

- Aceptar el pago defectuoso sin observaciones, en cuyo caso la deuda queda extinguida por dación en pago.

- Aceptar el pago defectuoso pero con las debidas reservas, lo cual habilita exigir la adecuación o la indemnización.

Si el vicio es desconocido, pero no debiera serlo, teniendo en cuenta la profesión u oficio del comprador, tampoco opera la garantía. Aquí se aplica una regla de debido cuidado; el obrar negligente del comprador no se halla amparado por la ley.

III. Defecto oculto.

Así lo establece el artículo 2138 de la ley E-0026 (2164 Cód. Civil).

¿Qué es lo oculto? Nuestro Derecho en el artículo 2147 de la ley E-0026 (2173 Cód. Civil) nos dice que oculto es lo no aparente, y siguiendo a Planiol y Ripert "El vendedor no responde de los vicios aparentes...; al comprador le corresponde verlos; la sorpresa respecto de ellos sólo puede ser efecto de una imprudencia del comprador" (1996, p. 934).

La ley solo nos brinda un marco de determinación, es por ello que el concepto debió ser construido por la doctrina. Según el Código Civil italiano, el vicio no tiene ese carácter cuando "es fácilmente reconocible". Para Salvat (1946, p. 413) es oculto si no pudo ser descubierto 
tras un examen atento y cuidadoso de la cosa, pero a ello agrega que si valiéndose de terceros expertos pudo ser descubierto no es oculto. Ese criterio era criticado por Borda (2008, p. 226), quien decía que no era posible andar por la vida acompañado de expertos.

En general se ha reconocido un estándar de conducta medio, de manera que el vicio se considera oculto cuando el adquirente emplea la diligencia adecuada al caso, según las circunstancias de tiempo, lugar y personas y aun así no es posible detectarlo (es una aplicación del artículo 482 de la ley E-o026 - 512 del Cód. Civil). Ello significa que en principio no se requiere la necesidad de hacerse asesorar por un perito, pero sí la complejidad del caso lo exigiere esta omisión puede perjudicar al comprador, por ejemplo si un abogado compra un microscopio comparador de barrido, no puede alegar su ignorancia sobre el asunto para desconocer un vicio que hubiera sido fácilmente detectable por un estudiante de física o química.

El problema es que lo oculto o aparente es una cuestión de hecho y de grados. En los extremos podemos ver con claridad qué es oculto y qué es aparente, pero en medio hay cuestiones fronterizas muy difíciles de dilucidar que deben ser resultas bajo la apreciación del juez. La prueba del carácter oculto del vicio está a cargo del adquirente (artículo 2142 de la ley E-0026 - 2168 Cód. Civil).

En el fallo Masero de $2008^{4}$ se analiza la venta de una explotación agropecuaria en el sur, como un negocio complejo, es decir; el inmueble, más el establecimiento y las ovejas. El vendedor se asegura la supervisión de la explotación hasta el completo pago del precio. Luego aparece una enfermedad en gran parte de los animales, por lo que se intenta una acción de rescisión por vicios redhibitorios y se exigen daños y perjuicios por existir supuesta mala fe del enajenante. El tribunal entendió que la enfermedad era exótica por no estar incluida dentro de los controles SENASA y calificaba el vicio de oculto. También dijo que el hecho que el enajenante se asegurara la supervisión del establecimiento daba cuenta que no había mala fe de su parte, no obstante hizo lugar a la demanda de rescisión del negocio jurídico integral, es decir; también la compraventa del inmueble y no solo la venta de ovejas, sin admitir la indemnización pretendida.

\section{Gravedad del defecto.}

El vicio no solo deber ser oculto, además debe ser grave. Según el artículo 2138 de la ley E-0026 (2164 Cód. Civil), el vicio debe ser de tal entidad que debe tornar la cosa "impropia para su destino, si de tal modo disminuye el uso de ella que al haberlos conocido el adquirente, no la habría adquirido, o habría dado menos por ella".

Vicios de poca monta, insignificantes, no son suficientes para poner en ejecución la garantía. El tráfico seria imposible si se exigiera que las cosas fueran perfectas.

\footnotetext{
${ }^{4}$ Masero, Antonio c/Gunther Moschkomitz, Jacqueline s/Sumario. Cámara de Apelaciones en lo Civil, Comercial y de Minería de
} San Carlos Bariloche. 16-04-2008. IJ-XXIX-847. 
La impropiedad no es inutilidad total, sino afectación sustancial del destino de la cosa, aunque algunos autores entienden que "la impropiedad se manifiesta en una supresión del uso de la cosa" (Rinessi, 1999, T.I, p. 439), no hay razones que nos lleven a exigir estándares tan elevados. Esa impropiedad tiene un complemento subjetivo, porque para determinarse debe tenerse en cuenta que el contratante no hubiera adquirido la cosa o no hubiera pagado el precio que pagó por ella. Nicolau (2009, T.I, p. 392/3) critica el sentido abstracto que se utiliza, porque hace uso de estándares de mercado y no toma en consideración el destino concreto que el adquirente le daría a la cosa. Por ello es partidaria de tomar muy en cuenta si el adquirente informó al enajenante el destino que daría a la cosa, no es lo mismo una persona que compra una salamandra antigua para decorar un living, y luego intenta vicios redhibitorios porque tiene una fisura que se hallaba bien disimulada por la pintura y que al ser encendida llena de humo el salón. La fisura puede hacer impropia la salamandra para el destino calefacción, pero no para el destino decorativo para el cual fuera adquirida.

La gravedad del vicio también es una cuestión de hecho y de grados, con casos fronterizos muy difíciles de dilucidar que deben ser resueltos por el juez.

Si el vicio no es grave, no es redhibitorio, y así lo expresa Velez en la nota del articulo 2164 Cód. Civil (artículo 2138 de la ley E-0026), pero como explica Alterini (2009, p. 503) ello no quiere decir que no pueda dar lugar a reclamos. Un vicio leve da lugar a reclamo por aplicación de reglas generales, no por las especiales de vicios redhibitorios, porque afectan el cumplimiento exacto de la obligación que el acreedor tiene derecho a requerir.

\section{Defecto existente al tiempo de la adquisición.}

El punto temporal de referencia no es la celebración del contrato, sino de la adquisición de los derechos sobre la cosa. Eso se produce cuando se trata de cosas muebles con la tradición, y en caso de inmuebles con la tradición, escritura y registración.

El vicio no debe ser sobreviniente, sino existente al tiempo de la adquisición. Puede encontrarse en estado germinal ${ }^{5}$ y desarrollarse posteriormente, por ejemplo un animal con una enfermedad en estado de incubación.

Una excepción importante se da en los contratos de locación de cosas, porque puede resultar que al momento de la entrega, la cosa no tengas vicios, pero si los mismos son sobrevinientes, el artículo 1495 de la ley E-0026 (1525 Cód. Civil) faculta al locatario a aplicar el régimen de vicios redhibitorios para resolver el contrato o pedir una rebaja.

Sostiene Nicolau (p. 396) que la prueba de la existencia del vicio, al tiempo de la transmisión es casi diabólica y se halla a cargo del adquirente, según lo dispone el artículo 2142 de la ley

\footnotetext{
${ }^{5}$ La jurisprudencia ha desarrollado esta idea del vicio germinal, "puede considerarse vicios redhibitorios a los que existan en germen al momento de la adquisición, aunque sólo se haya manifestado después, por ejemplo, la aparición de una mancha de humedad por un defecto de construcción" CNCiv., sala D, marzo 7/1975 - ED, 63-161.
} 
E-0026 (2168 Cód. Civil), solución que ha sido criticada, alegándose que debiera presumirse si aparece muy próximo a la entrega de la cosa.

VI. La cosa defectuosa tuvo que ser transmitida para su dominio, uso o goce por título oneroso.

Afirma el artículo 2139 de la ley E-0026 (2165 Cód. Civil) que "Las acciones que en este título se dan por los vicios redhibitorios de las cosas adquiridas, no comprenden a los adquirentes por título gratuito”. Aquí, como en la evicción, vemos con claridad el carácter objetivo de su fundamento. No es la frustración de las expectativas de una contratante lo que da origen a esta figura, sino el desequilibrio prestacional. Si no hay prestación y contraprestación no resulta posible aplicar los vicios redhibitorios.

Es un elemento natural de los contratos onerosos, pero puede pactarse en cualquier contrato.

\section{OBJETOS SOBRE LOS CUALES RECAE LA GARANTÍA}

Recae sobre cosas muebles e inmuebles, y por lo dispuesto en el artículo 2285 de la ley E-0026 (2311 Cód. Civil) también se hace aplicable a energías y fuerzas naturales susceptibles de apropiación.

En principio, no sería aplicable a derechos intelectuales dado que no puede haber vicio en la materialidad, pero si en el derecho, por lo que podría ser objeto de la garantía de evicción. No obstante Salvat (1946, p. 415) consideraba posible algunas aplicaciones en materia de derechos intelectuales, pero sin dar mayores precisiones. Entiendo que este caso sería posible cuando se trate de la venta o concesión de licencia de un software que por defectos en la programación no cumple con el fin para el cual fue creado.

\section{SUJETOS DE LA GARANTÍA}

Adquirente y enajenante a título oneroso, y sus sucesores, en sentido amplio.

De igual modo que en la garantía por evicción, el sucesor singular, aunque sea a título gratuito puede reclamar al transmitente a título oneroso de su causante, aunque no pueda reclamárselo a su causante mismo (aplicación analógica del artículo 2070 de la ley E-0026 - 2096 Cód. Civil). Esto se mantiene en el anteproyecto de Código Civil y Comercial de 2012 (artículo 1035).

Sin embargo, el subadquirente no puede reclamar al originario, si el vicio era aparente al momento de la transmisión original, y oculto al momento de la segunda transmisión.

Según el artículo 2145 de la ley E-0026 (2171 Cód. Civil), "Está igualmente libre de res- 
ponsabilidad por los vicios redhibitorios si el adquirente obtuvo la cosa por remate, o adjudicación judicial". Pero vale precisar que no toda venta por remate excluye la responsabilidad, solo las ordenadas por un tribunal y realizadas bajo su autoridad, de modo tal que no aplica a ventas voluntarias realizadas a través de subastas. Esta solución se justifica porque la intervención judicial excluye la posibilidad de mala fe, existe un ambiente de publicidad que rodea la venta, y la actuación del vendedor no es determinante ni siquiera en la fijación del precio.

\section{MODIFICACIÓN DE LA GARANTÍA POR VÍA CONTRACTUAL}

¿Pueden modificarse las garantías por vía contractual? La respuesta es afirmativa porque no hay orden público comprometido, solo el interés de los particulares.

Los vicios redhibitorios son efectos naturales de los contratos onerosos, están regulados en la ley, y se aplican aún en ausencia de estipulaciones de las partes. Pero si las partes deciden introducir clausulas con el fin de ampliar, restringir o suprimir éstas garantías, están habilitadas pero con algunas condiciones. Este es el criterio del actual Código que ha sido mantenido en el artículo 1052 del Proyecto de Código Civil y Comercial.

Según el artículo 2140 de la ley E-0026 (2166 Cód. Civil) "las partes pueden restringir, renunciar o ampliar su responsabilidad por los vicios redhibitorios, del mismo modo que la responsabilidad por la evicción, siempre que no haya dolo en el enajenante”. En similar sentido se expresa el artículo 2143 de la ley E-0026 (2169 Cód. Civil) cuando enuncia que " $L a$ estipulación en términos generales de que el enajenante no responde por vicios redhibitorios de la cosa, no lo exime de responder por el vicio redhibitorio de que tenía conocimiento, y que no declaró al adquirente”. Es decir, se hace prevalecer el principio de autonomía privada, pero con un límite, el dolo del enajenante, si este conocía el vicio y no lo denunció la cláusula restrictiva no opera. Pero si lo denunció y después se excluyó de la garantía es perfectamente válida. Lo que impide el régimen legal es amparar la mala fe.

También se puede ampliar la garantía y así lo determina expresamente el artículo 2141 de la ley E-0026 (2167 Cód. Civil) "Pueden también por el contrato hacerse vicios redhibitorios de los que naturalmente no lo son, cuando el enajenante garantizase la no existencia de ellos, o la calidad de la cosa supuesta por el adquirente. Esta garantía tiene lugar aunque no se exprese, cuando el enajenante afirmó positivamente en el contrato, que la cosa estaba exenta de defectos, o que tenía ciertas calidades, aunque al adquirente le fuese fácil conocer el defecto o la falta de la calidad". Cabe una critica al artículo que dice que las partes "pueden... por el contrato hacerse vicios redhibitorios de los que naturalmente no lo son...", en rigor de verdad lo que se hace es extender el régimen de vicios redhibitorios a aquellos que no lo son; no se crean nuevos vicios redhibitorios.

Entonces para extender la garantía de vicios redhibitorios, por vía contractual, a vicios 
que no lo son, se requiere que el enajenante:

- Garantice la inexistencia de vicios.

- Garantice la calidad de la cosa supuesta por el adquirente.

- Afirme en el contrato que la cosa esta exenta de defectos.

- Afirme en el contrato que la cosa tiene ciertas calidades.

Un modo usual de extensión de garantía se da cuando el enajenante garantiza contractualmente el buen funcionamiento de la cosa por un cierto tiempo (p.ej: una máquina). Vale precisar que en los dos últimos casos, opera la extensión de la garantía aun cuando al adquirente le fuese fácil conocer el defecto o la falta de calidad. También aplicando la regla de la buena fe, no opera la extensión si el adquirente conocía efectivamente el vicio porque se supone que contrató bajo esas condiciones.

\section{EFECTOS DE LOS VICIOS REDHIBITORIOS. ACCIONES.}

Las acciones con las que cuenta el adquirente, nos llegan directamente desde el antiguo Derecho Romano. El adquirente tiene en sus manos dos opciones, la acción redhibitoria para reclamar la resolución del contrato, de modo que ambas partes deben reintegrarse precio y cosa, y la acción estimatoria o quanti minoris ${ }^{6}$ por la cual puede solicitarse una reducción proporcional del precio una vez restado el costo del defecto.

Así lo establece el artículo 2148 de la ley E-0026 (2174 Cód. Civil) "el comprador tiene la acción redhibitoria para dejar sin efecto el contrato, volviendo la cosa al vendedor, restituyéndole éste el precio pagado, o la acción para que se baje del precio el menor valor de la cosa por el vicio redhibitorio".

Según el artículo 2149 de la ley E-o026 (2175 Cód. Civil) "El comprador podrá intentar una u otra acción, pero no tendrá derecho para intentar una de ellas, después de ser vencido o de haber intentado la otra." Son acciones alternativas, no acumulables. El fundamento de esta prescripción parecería ser el valor de cosa juzgada que adquiere el vicio, si ya fue rechazado en sede judicial no puede volver a discutirse bajo otra acción; pero el artículo mismo introduce un variante que no se condice con esta lógica, dado que no solo opera luego de haber sido vencido en juicio sino de haber “intentado" la acción, y por aplicación de reglas procesales, esto se concreta al momento de notificada la demanda. Según Salvat (1946, p. 419) la razón de esta prescripción normativa es que una vez intentada una acción, la misma se halla pendiente por lo que corresponde esperar el resultado.

Si el adquirente triunfa en la acción frente a un enajenante de buena fe tiene derecho a la

\footnotetext{
${ }^{6}$ Traducción: cuánto menor, o en cuanto menos, del latín.
} 
restitución del precio más intereses, y debe la entrega de la cosa, más los frutos y productos. Si el enajenante es de mala fe debe restituir el precio y pagar daños y perjuicios7. En la quanti minoris, según la opinión mayoritaria no cabría indemnización, dado que la decisión del adquirente de conservarla da cuenta que se queda con la cosa porque le conviene y no le ha producido daño. Mosset Iturraspe (2008, p. 489) recuerda que estas eran acciones edilicias ${ }^{8}$ y como regla general no aparejaban reparación por daños sufridos por el comprador.

I. Excepciones al derecho a optar por las acciones.

En principio, el adquirente puede optar libremente por cualquiera de las 2 acciones, pero hay algunas excepciones de orden práctico y otras fundadas en la buena fe.

En primer lugar encontramos el caso de la venta en conjunto, cuando se hayan adquirido dos o más cosas en masa, formando un todo y por un solo precio (artículo 1309 de la ley E-0026 - 1339 Cód. Civil); en ese caso no cabe exigir la resolución del contrato y solo habilitaría la acción estimatoria. Si se hubiera establecido un precio por cada cosa, la acción redhibitoria podría intentarse solo en referencia a la cosa afectada y no a todo el contrato. Pero si esa cosa afectada fuera esencial al negocio podría afectar al contrato mismo, por ejemplo un persona que adquiere al mismo proveedor, en un mismo contrato, equipamiento informático para una empresa (PCs, impresoras, software, cables de red, etc.) si una PC tiene defectos ocultos se puede solicitar la restitución de lo pagado por esa máquina, pero si el defecto se halla en el software que hace funcionar los equipos impidiéndoles cumplir su labor e integrarse en red, puede resolverse el contrato mismo aun cuando todo el hardware funcione perfectamente.

La otra excepción viene dada por la pérdida de la cosa por causa del vicio. En ese caso solo cabría la acción redhibitoria, así lo estipula el artículo 2152 de la ley E-o026 (2178 Cód. Civil) "Si la cosa se pierde por los vicios redhibitorios, el vendedor sufrirá la pérdida y deberá restituir el precio. Si la pérdida fuese parcial, el comprador deberá devolverla en el estado en que se hallare para ser pagado del precio que dio".

Ahora bien, si la pérdida no se produjera por el vicio se aplica el artículo 2153 de la ley E-0026 (2179 Cód. Civil) que estipula que "Si la cosa vendida con vicios redhibitorios se pierde por caso fortuito, o por culpa del comprador, le queda a éste sin embargo, el derecho de pedir el menor valor de la cosa por el vicio redhibitorio". En este caso solo se podría intentar la quanti minoris. El fundamento es que la causa de la pérdida le es extraña al enajenante, y no hay razón para que se beneficie de ella.

\footnotetext{
${ }^{7}$ La jurisprudencia también ha aplicado daños morales en estos casos, por ejemplo por publicar un aviso de venta de un inmueble como si hubiese estado en perfectas condiciones, cuando en realidad no lo estaba ("Monchietti, Nélida E. c/Contel, Mónica G. s/Daños y Perjuicios". Cámara Nacional de Apelaciones en lo Civil - Sala L. 05-11-2007. IJ-XXVIII-485)

${ }^{8}$ Término romano que remite al Edicto de los Ediles. Los 2 edictos donde se hallan los orígenes de la figura son edictum de iumentis vendutis y el edictum de mancipis vendutis, el primer edicto se refiere exclusivamente a la compraventa de jumentos, $\mathrm{y}$ el segundo a los esclavos.
} 


\section{Acción quanti minoris}

Si bien el comprador solo tiene estas dos acciones disponibles, la quanti minoris, es la vía idónea cuando el adquirente no quiere desprenderse del bien, y no fuera posible repararla (por ejemplo por falta de repuestos), pero surge la pregunta, ¿qué pasa si le resulta posible reparar el defecto y no tiene interés en rescindir el contrato ni pedir reducción de precio?, en ese caso Mosset Iturraspe (2008, p. 489) lo considera posible y cita un fallo de la Cám. $2^{\circ}$ Civ. y Com. de Santa Fe (Juris, 4-147) que hizo aplicable la ejecución forzada indirecta (artículo 475 inc. 3 , ex 505, inc. 3 CC) disponiendo el arreglo de la cosa a costa del enajenante.

Cuando se intenta con éxito la quanti minoris, en general lo que ha hecho la jurisprudencia es ajustar la reducción del precio a un equivalente al costo de subsanación del defecto, cuando esto ha sido posible ${ }^{9}$. Este tema ha merecido poco tratamiento en nuestro Derecho, pero en el Derecho Comparado ha empezado a tener una progresiva importancia, porque la reducción del precio, por un lado mira a la conservación del contrato y por otro al reequilibrio sinalagmático de las prestaciones.

El mayor valor de la acción estimatoria radica en el punto que menos se ha ocupado nuestra doctrina, la identificación de un método apropiado para su cálculo. Esa falta de tratamiento es inexplicable porque hay muchos métodos disponibles, no es necesario dejar todo librado al soberano arbitrio del juez. Ferrante explica que existen "esencialmente tres familias de métodos de cálculo de reducción del precio: uno equitativo, uno proporcional y otro de resta” (Ferrante, 2011. p.7), y los analiza en 57 páginas. Este no es el momento para desarrollarlo, pero quiero advertir esta gruesa omisión de nuestro Derecho.

La falta de un método claro para definir la reducción de precio obliga a revisar el valor de la acción estimatoria. Un contrato con un precio modificado por el juez, afecta un elemento central de lo convenido y puede resultar insatisfactorio incluso para ambas partes. Yo soy partidario de ser muy cuidadoso en la intervención judicial integrando contratos o modificando cláusulas contractuales, que terminan ligando a las partes en un contrato que no quieren o que no hubieran acordado en esos términos.

El tráfico moderno ha dado lugar a una figura muy interesante que es la renegociación contractual (Nicolau, 2002), la idea es que el contrato no es algo estático sino dinámico que debe ajustarse a las vicisitudes del tiempo, y que habilita la posibilidad de permanentes adecuaciones de común acuerdo. En este caso creo que se debería habilitar la renegociación, y en caso de desacuerdo operar la rescisión contractual y liberar a los contratantes. No es una idea muy original, estoy haciendo un uso selectivo de reglas contenidas en los principios UNIDROIT (2004) para la compraventa internacional de mercaderías en el caso de hardship. 
II. Acción redhibitoria. Campo de aplicación.

La acción redhibitoria procede en la compraventa y en la locación de cosas, pero el artículo 2154 de la ley E-0026 (2180 Cód. Civil) establece que "Lo dispuesto respecto a la acción redhibitoria entre comprador y vendedor, es aplicable a las adquisiciones por dación en pago, por contratos innominados, por remates o adjudicaciones, cuando no sea en virtud de sentencia, en las permutas, en las donaciones, en los casos en que hay lugar a la evicción y en las sociedades, dando en tal caso derecho a la disolución de la sociedad, o la exclusión del socio que puso la cosa con vicios redhibitorios”. Visto tal amplitud la doctrina ha entendido que es extensivo a todos los contratos en los que haya precio.

Valga una aclaración, los vicios redhibitorios se aplican a las donaciones pero solo en los mismos casos que la evicción. Es decir, en principio el donante no debe la garantía, pero como lo dispone el artículo 2120 de la ley E-0026 (2146 Cód. Civil) contiene algunas excepciones como donaciones de mala fe, con cargo o remunerativas.

\section{PRESCRIPCIÓN}

Este es un tema que plantea enormes dificultades.

Según el artículo 3999 de la ley E-0026 (4041 Cód. Civil) "Se prescribe por tres (3) meses, la acción redhibitoria para dejar sin efecto el contrato de compra y venta; y la acción para que se baje del precio el menor valor por el vicio redhibitorio".

Por otra parte el artículo 676 de la ley F-0067 (473 Cód. Comercio) estipula que "Las resultas de los vicios internos de la cosa vendida, que no pudieren percibirse por el reconocimiento que se haga al tiempo de la entrega, serán de cuenta del vendedor durante un plazo, cuya fijación quedará al arbitrio de los Tribunales, pero que nunca excederá de los seis meses siguientes al día de la entrega”.

En el Derecho Civil se habla de tres (3) meses, pero sin establecer desde cuándo empieza a correr el término, en el Derecho Comercial se estipulan seis (6) meses desde el día de la entrega, como plazo máximo. En ambos casos se habla solo de compraventa, y se omite referencia a los otros contratos.

En el caso comercial, seis (6) meses no es el plazo de prescripción de la acción, sino un período de tiempo para advertir o percibir los defectos. Los ostensibles deben hacerse al momento de la entrega, los ocultos hasta seis (6) meses después. Dentro de ese período el comprador debe cursar la protesta, que es único medio que dispone para poner en evidencia que el vicio fue descubierto durante el plazo legal, luego contará desde ese momento de 4 años antes que prescriba la acción por aplicación del artículo 1070 de la ley F-0067 (847 Cód. Comercio). 
Así lo ha entendido también la jurisprudencia ${ }^{10}$.

En el Derecho Civil no hay norma que fije plazo para que el vicio se haga ostensible, solo se habla de la prescripción de la acción. Tal vez se haya buscado un punto de equilibrio entre un tiempo indefinido para descubrir pero ajustado a un tiempo muy acotado para demandar. Pero el Derecho es contrario a consagrar tiempos indefinidos, por regla general todo tiene un fin y no hay razones para pensar que este punto sea la excepción, razón por la cual entiendo que no puede llevarse el plazo máximo para descubrir más allá de lo dispuesto para la prescripción decenal.

Para el resto de los contratos que no sean compraventa, algunos consideran que deben aplicarse estas mismas reglas por analogía, y otros la prescripción ordinaria.

El proyecto de Código Civil y Comercial conjuga un doble plazo de caducidad de la garantía, amén del plazo de prescripción. Establece la carga de denunciar vicios dentro de sesenta (60) días de haberse manifestado (artículo 1054). A continuación (artículo 1055) establece el plazo de caducidad de la garantía, de tres años para los inmuebles y seis meses para los muebles; son plazos que pueden aumentarse convencionalmente (nada dice de disminuirse). Luego establece que en materia de prescripción se remite a las reglas generales.

\section{LOS VICIOS REDHIBITORIOS SEGÚN EL ANÁLISIS ECONÓMICO DEL DERECHO.}

Una vez analizado el instituto desde una perspectiva dogmática, pretendo que lo podamos estudiar desde una perspectiva diferente, en este caso el análisis económico del derecho.

Horacio Spector (2003, p. 241) afirma que "en la Edad Media, la doctrina jurídica iusprivatista comenzó a desarrollar una estructura teórica capaz de explicar y sistematizar el conjunto de normas de Derecho Romano. Este proceso culminó durante los siglos XVIII y XIX con la redacción de los Códigos civiles europeos y latinoamericanos. Luego de que la codificación

\footnotetext{
10 "Las acciones reguladas a las resultas de los vicios internos de la cosa vendida, que no pudieran haberse percibido por el reconocimiento que se hiciera al momento de la tradición, prescriben sin remedio al vencer el plazo de seis meses contados desde el día siguiente al de la entrega de la cosa, contemplado en el art. 473 del Cod. de Comercio ("Casa Niccolini S.A. c/ Martín, Orlando s/ Cobro de australes" - CC0000 - TL 9631 RSD-19-79 S - 16-08-90; Citar: elDial - W8E17). También un fallo reciente revocó la sentencia de primera instancia que había declarado prescripta la acción fundada en los vicios redhibitorios del automóvil vendido. Dicha resolución revocatoria tuvo en cuenta que en una compraventa mercantil existe un término improrrogable para la comprobación del defecto constitutivo de un vicio redhibitorio que es el plazo de seis meses fijado en el Cód. Com. art. 473, y que el mismo es diverso del plazo de prescripción. En efecto, mientras que el término del art. 473 del Cód. Com. tiene por finalidad liberar al vendedor de aquellos vicios advertidos luego de vencido ese período, el de prescripción recién comienza a correr al fenecer el primero; pues, la posibilidad de demandar nace del reclamo efectuado al percibirse y reclamarse (extrajudicial o judicialmente) el vicio dentro de ese plazo semestral (“Fernández, Walter R. y Otro c/Renault Arg. SA s/Ordinario". CNac. Apel. en lo Comercial-Sala D. 16-02-2012. IJ-LXVII-645).
} 
fue puesta en práctica, y completada con la sanción del Código Civil alemán (BGB), la ciencia jurídica comenzó a declinar en vitalidad intelectual. Aunque los juristas todavía trabajan en la sistematización de las normas codificadas y, en particular, de las decisiones judiciales que buscan ajustar el Código a las nuevas circunstancias económicas, sociales y tecnológicas, esta actividad carece de la sofisticación teórica que marcó los estudios civilistas de la precodificación, en gran medida, esto se debe al hecho de que los juristas completaron, a todos los efectos prácticos el proceso de redescubrimiento y sistematización del Derecho Romano que sentó las bases para la codificación”.

Luego continúa diciendo que "en las últimas décadas, los juristas norteamericanos han producido una revolución intelectual al aplicar la economía y la filosofía moral al estudio de instituciones jurídicas particulares. Los analistas económicos del derecho y los filósofos del derecho compiten en tratar de ofrecer la explicación más exitosa de diferentes campos del common law" (Spector, 2003, p. 241-2).

En lo que respecta al análisis económico del derecho, su principal preocupación, que constituye una materia central de la ciencia económica, es “... saber cómo debe utilizar una sociedad los recursos limitados de que dispone, para conseguir el mayor grado de satisfacción de las necesidades” (Schäfer y Ott, 1991, p. 21). Esa preocupación se denomina eficiencia.

Para el análisis económico del derecho los contratos sirven para facilitar los intercambios voluntarios, destinando los recursos de usos menos valiosos a otros más valiosos (Posner, 2000, p. 90). La idea central de la teoría económica es que las personas son los mejores jueces de sus propios intereses y que los intercambios voluntarios incrementan su bienestar. Los contratos maximizan el bienestar de las partes, en tanto cada una revela, por medio de sus actos, que valora más el derecho sobre el bien recibido que el entregado a cambio. En suma, los intercambios son mutuamente ventajosos para las partes. Entonces si cada contratante recibe algo que valora más, se comprueba un excedente a favor de ambas partes.

En un mundo sin costos de transacción (Coase, 1960), y donde todos los agentes dispongan de información perfecta y plena, la existencia de un derecho de contratos sería innecesaria. Pero como ese mundo ideal no existe "el sistema de intercambios voluntarios se derrumbaría por completo sin un derecho de contratos" (Posner, 2000, p. 91).

Vemos que en el mundo real no siempre existe buena fe en los contratantes, y es menester forzarlos a cumplir con lo acordado, y también existen costos de transacción. Posner (2000) señala que los dos papeles principales que cumple el derecho contractual son resolver los problemas de oportunismo y de contingencias imprevistas. El oportunismo es un fenómeno que implica la posibilidad de que alguna de las partes incumpla su promesa o aproveche la vulnerabilidad del otro contratante para adoptar una acción que vulnera el espíritu de lo pactado, y nos brinda un ejemplo, si A tiene una vaca que valora en 30, y la pone en venta, puede encontrarse que B (que la valora en 50) le ofrezca 50 pagaderos inmediatamente y C (que la valora en 100) le ofrezca 75 pero pagaderos en una semana porque no tiene ahora el efectivo, si se celebra un 
contrato entre $\mathrm{A}$ y $\mathrm{C}$, y no existieran normas que obligaran a $\mathrm{C}$ a cumplir lo prometido, lo racional sería que A no se arriesgue y que la vaca termine en manos de B, que la valora menos.

Las contingencias imprevistas son situaciones en las cuales se produce un fenómeno externo que altera el contexto en el cual se pactaron las obligaciones contractuales, y que hace que algo que resultaba beneficioso para alguna de las partes (o para ambas) pase a ser inconveniente.

Evicción y vicios redhibitorios son estudiados en el análisis económico del derecho (Coloma, p. 64) como situaciones de intervenciones de derecho contractual tendientes a resolver fracasos de mercado originados en problemas de información asimétrica. Los vicios redhibitorios son vistos como casos de afectación de los contratos basadas en problemas de información, porque la ineficiencia del contrato original se debe a que alguno de los contratantes no tuvo disponible la información adecuada para prever que estaba efectuando un intercambio contrario a sus intereses (y, antes bien, creyó que el contrato lo beneficiaba).

El análisis económico del derecho reconoce que la situación en la cual se comercia un bien, implícita o explícitamente, garantizado contra vicios redhibitorios implique un precio mayor que una situación en la cual no existe dicha garantía. Ello es así porque el enajenante está transmitiendo un cosa más una garantía (cosa + cobertura en caso de probabilidad de ocurrencia de defecto), si esto no existiera, el comprador para cubrirse debería tomar a su cargo los costos de un estudio exhaustivo de cada cosa adquirida (cosa + estudio de inexistencia de defectos), y eso sería, en general, más costoso que la garantía.

Según el análisis económico del derecho el marco de referencia es el contrato perfecto, entonces lo correcto es imputar la pérdida derivada de un riesgo a la parte que se hubiera hecho cargo de él en una negociación contractual perfecta, esto es donde existiera información plena y completa, y se evaluara la totalidad de los riesgos y se asignara cada uno a quien pueda afrontarlo a menor costo. En otros términos, la reproducción de las cláusulas que las partes hubieran negociado en condiciones ideales.

En ese contexto de negociación, no se considera racional, desde el punto de vista económico, que un sujeto invierta en prevención del daño más que el costo del daño mismo. A eso se le denomina principio del evitador más barato de costos o cheaper cost avoider, en su denominación original en inglés. Este es un principio aplicable a supuestos de daños bilaterales, es decir cuando tanto dañador como víctima pueden tomar precauciones para evitar el accidente.

Según el cheaper cost avoider, si tanto el agente causal del daño como el damnificado pueden evitar el accidente, entonces se debe cargar con la responsabilidad a aquel sujeto que lo pudo haber evitado de forma más económica. Sabremos quién es el agente que podía evitar el daño de modo más barato, luego de aplicar una formula consistente en evaluar los costos del accidente, descontando la probabilidad de su ocurrencia, y contrastando esta cifra con los costos de las prevenciones.

Esto que parece tan complejo es lo que hace nuestro régimen de vicios redhibitorios, si es más económico para el adquirente que para al enajenante conocer los riesgos, no está habi- 
litado a invocar este régimen objetivo, esto es cuando "los conocía o debía conocerlos por su profesión u oficio" (artículo 2144 de la ley E-0026 - ex 2170 Cód. Civil).

Como acabamos de ver nuestro régimen de vicios redhibitorios responde perfectamente a una lógica de eficiencia económica.

\section{CONCLUSIONES}

La pregunta central en materia de vicios redhibitorios, es si entregar una cosa con vicios ocultos puede calificarse como cumplimiento del contrato. En el Derecho, desde tiempos de la antigua Roma se ha entendido que no. Pero entonces cabe la siguiente pregunta ċpor qué la existencia de vicios ocultos no sirve para que se declare, simplemente, que ha sido infringida la obligación principal de entregar la cosa vendida en las condiciones acordadas? La única respuesta consistente es apelar a razones de utilidad, a cuestiones prácticas para facilitar el tráfico.

El régimen de los vicios ocultos se sustenta en fundamentos económicos, no jurídicos como en la evicción, y tiende a asegurar al adquirente una posesión útil (Castán Tobeñas. 1993. p. 121).

Es un supuesto de responsabilidad objetiva del transmitente, quien debe la garantía aunque sea de buena fe. La existencia de mala fe solo sirve para agravar la situación de éste, y habilitar una indemnización por daños y perjuicios, pero ello es independiente de la restitución del precio que se debe en todos los casos.

Queda claro que lo que se pretende es restablecer el equilibrio prestacional. El adquirente ha pagado un precio con el fin de obtener un bien, teniendo en miras determinadas utilidades de la cosa. Esas utilidades, no surgen de su imaginación sino que son propias del destino de la cosa, pero si no sirve para eso, el comprador se ve perjudicado. De allí que esta garantía permita la restitución recíproca del precio y la cosa, o bien la disminución del precio en medida equivalente al costo del defecto.

Las modernas teorías del Análisis Económico del Derecho (AED), coinciden con la solución pero le dan al asunto un nuevo abordaje mirando la utilidad social y no el equilibrio prestacional. Los vicios son casos de daños bilaterales, en cuya detección pueden invertir tanto adquirente como enajenante, y corresponde cargar con los riesgos del mismo a aquel sujeto que de manera más económica pueda evitarlos.

\section{REFERENCIAS BIBLIOGRÁFICAS}

Alterini, Atilio Anibal (2009). Contratos. Abeledo Perrot. Buenos Aires. 
Badenes Gasset, Ramon. (1995). El contrato de compraventa. Tomo I. $3^{\text {ra }}$ edición. José María Bosch Editor. Barcelona.

Borda, Guillermo (2008). Manual de Derecho Civil. Contratos. La Ley. Buenos Aires.

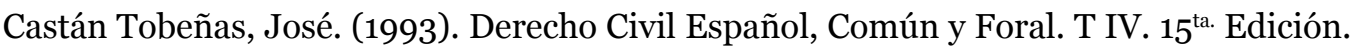
Reus. Madrid.

Coase, Ronald (1960). "The problem of social cost”, en Journal of Law and Economics, $\mathrm{N}^{0}$ 3. Traducción en español, "El problema del costo social”, en Revista de Estudios Públicos, $\mathrm{N}^{0}$ 1. Págs. 81-134.

Coloma, Germán. Apuntes para el análisis económico del Derecho Privado argentino, en Latin American and Caribbean Law and Economics Association works.bepress.com/german coloma/25

Cooter, Robert y Ulen, Tomas (1997). Derecho y Economía. Fondo de Cultura Económica. México D. F.

De Reina Tartiere, Gabriel (coordinador. (2010). Contratos civiles y comerciales. Parte general. Heliasta. Buenos Aires.

Enciclopedia Jurídica Latinoamericana (2007). Tomo X. Rubinzal-Culzoni y Universidad Nacional Autónoma de México. Santa Fe.

Ferrante, Alfredo. "Nuevas tendencias en la cuantificación de la reducción del precio", en InDret 4/2011 www.indret.com/pdf/861_es.pdf

Garrido, Roque Fortunato y Zago, Jorge Alberto (1995). Contratos civiles y comerciales. Tomo I. Editorial Universidad. Buenos Aires.

Leiva Fernández, Luis (2002). Contratos civiles y comerciales. La Ley. Buenos Aires.

Mosset Iturraspe, Jorge (2008). Contratos. Rubinzal-Culzoni. Santa Fe.

Nicolau, Noemí (2002). "La revisión y renegociación del contrato como instrumentos útiles para su adecuación a las circunstancias sobrevenidas”, en Lexis Nexis. Jurisprudencia Argentina 2002-IV, 1058. 
Nicolau, Noemí (2009). Fundamentos de Derecho Contractual. Tomo I. La Ley. Buenos Aires.

Planiol, Marcel y Ripert, Georges. Derecho Civil. (1996). Editorial Pedagógica Iberoamericana. México D.F. Traducción de Leonel Pereznieto Castro, del Traité élémentaire de droit civil. (1946) 3a. ed. LGDJ. París.

Posner, Richard A. (2000). El análisis económico del derecho. Fondo de Cultura Económica. México D. F.

Rinessi, Antonio Juan (1999). Contratos. Tomo I. Mave. Corrientes.

Rojas, Ricardo; Schenone, Osvaldo; y Stordeur, Eduardo (2012). Nociones de análisis económico del derecho privado. Mayaprin. Guatemala.

Salvat, Raymundo M. (1946). Tratado de Derecho Civil Argentino. Tomo VI. La Ley. Buenos Aires.

Schäfer, Hans-Bernd y Ott, Claus. (1991). Manual de análisis económico del Derecho Civil. Tecnos. Madrid.

Spector, Horacio (2003). “Justicia y Bienestar. Desde una perspectivas de Derecho Comparado", en Doxa 26.

Spector, Horacio (Comp.) (2004). Elementos de análisis económico del derecho. Rubinzal-Culzoni. Santa Fe.

\section{CURRICULUM VITAE}

\section{Cristian Ricardo A. Piris}

Abogado. Magister en Derecho Privado. Doctor en Derecho

Profesor Adjunto por concurso Universidad Nacional del Nordeste.

cpiris@unne.edu.ar - cristian.piris@gmail.com - twitter.com/cpiris 